\title{
PORTABLE CW LINAC FOR COMMERCIAL APPLICATIONS
}

\author{
H.Deruyter ${ }^{*}$, R.Foose**, A.V.Mishin*, W.Sapp ${ }^{* * *}$, R.G.Schonberg ${ }^{* *}$, D.Skowbo* \\ American Science \& Engineering
}

\section{Abstract}

This paper continues our description of a new compact $\mathrm{CW}$ linac program started by Schonberg Research Corporation (SRC) under terms of a development contract. This work is now continued by High Energy Systems (HES) Division of AS\&E. HES has been formed based on the acquisition of SRC by AS\&E.

Since we published the design and the first experimental data on the $1 \mathrm{MeV} \mathrm{CW}$ linac [1], a complete test has been done as a continuation of the $\mathrm{CW}$ program. The accelerator is equipped with the local radiological shield and it can be operated on the manufacturing floor.

The linac can be used for a variety of commercial and scientific applications, which require high power electron beams such as NDT programs, sterilization of medical products, electron beam processing of composites and food irradiation.

In this paper, we will briefly describe the latest results and upgrades to the existing system.

\section{UPGRADES TO SYSTEM DESIGN}

The block diagram of the upgraded system is shown in Fig.1. We have replaced the $30 \mathrm{~kW}$ magnetron with a 30 $\mathrm{kW}$ klystron, driven by a $1 \mathrm{~W}$ solid-state source.

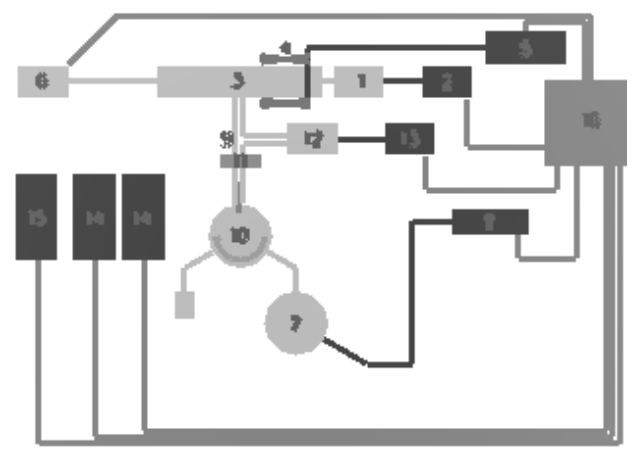

Figure 1: System block diagram

Electron beam is formed in the electron gun manufactured by Litton Industries (1). High voltage power supply (2) designed and built by HES provides 0 to $20 \mathrm{kV}$ to the egun accelerating gap. From the electron gun, the electron

\footnotetext{
${ }^{*}$ High Energy Systems Division of AS\&E (Santa Clara, California)

**** Headquarters located in Billerica, Massachusetts

** Consultant
}

beam is injected into a $1.3 \mathrm{~m}$ long linac section (3), where it is accelerated to the designed energy of $1 \mathrm{MeV}$. Two solenoids have been added to the existing three (4). Each solenoid is powered by a separate Sorenson power supply (5). The existing system is now capable of providing adjustable magnetic field close to $1000 \mathrm{G}$ peak, depending on the relative location of the solenoids. A $30 \mathrm{~kW}$ klystron (7) has replaced the magnetron operating at 2450 MHz. Upgraded Spellman power supply (8) is used to operate the klystron. The multiple beam klystron operating voltage range is similar to that of the previously used magnetron. A permanent periodic magnetic (PPM) focusing system used on this klystron permitting us to eliminate the electromagnet, used for the $\mathrm{CW}$ magnetron. A three-port RF circulator manufactured by AFT(13) is used to protect the klystron from the reflected power. All the components associated with the set-up using the magnetron, such as cooling fans for the magnetron "dome" window and the anode, $1 \mathrm{~kW}$ phase-locking klystron with power supply, the second RF circulator were removed from the existing system. The other components, described in [1] are unchanged. The assembly drawing which shows the linac position with respect to the "flying spot" wheel support is shown in Fig.2.

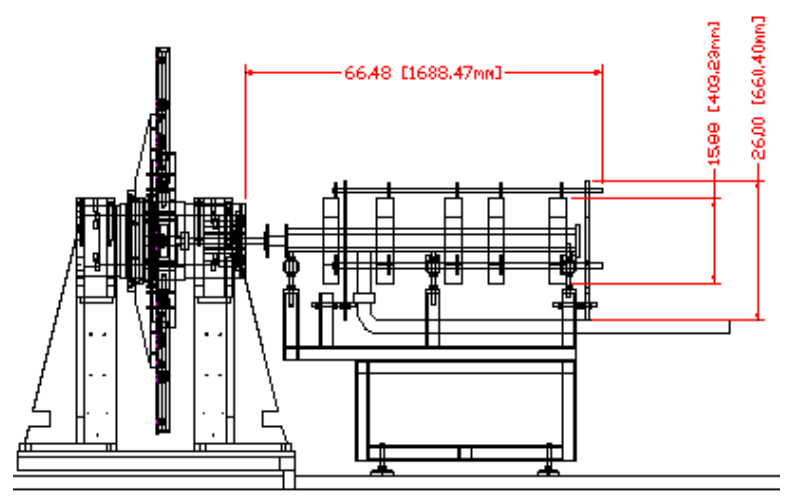

Figure 2: Present linac incorporated into a "demo"system

Other components such as magnetron, circulator, etc. have not been shown in order not to overload the drawing. 


\section{COMPONENTS DESIGN}

We have described the design of the accelerator structure in our previous publication [1]. The original design of the accelerator guide is based on the concept of combining two different structures: Alvarez and on-axis or sidecoupled structure. The cross section of the input coupler and Alvarez structure is shown on Fig. 3.

The concept permitted us to accelerate electron beam from low injection voltage of $12 \pm 6 \mathrm{kV}$ to $1 \mathrm{MeV}$ in $1.3 \mathrm{~m}$ long accelerator guide shown on Fig.3 using power source of only $30 \mathrm{~kW}$.

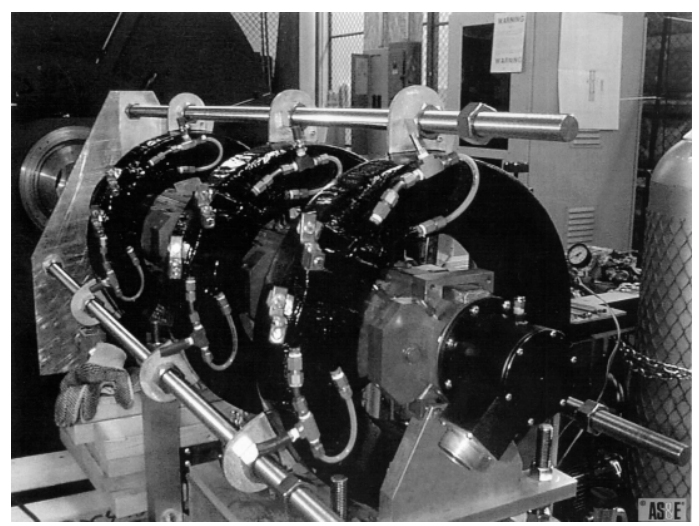

Figure 3: View of $1.3 \mathrm{~m}$ long accelerator guide.

Original calculations of beam dynamics and section geometry were made using a computer code AXIL. The preliminary results of these calculations were used for further more sophisticated beam dynamic simulation. The results of the computer simulation using codes Parmela and Beampath are shown in Fig.4 and 5. For the chosen geometry, a moderate field of $300-400 \mathrm{G}$ is required to transport the electron beam through the structure.

The guide was tuned to the designed frequency of 2450 $\mathrm{MHz}$. Separation of the neighboring resonances from the working resonance is close to $2 \mathrm{MHz}$ (Fig.6).

The $30 \mathrm{~kW}$, S-band, CW magnetron CWM-30S manufactured by California Tube Laboratory was originally used as a RF power source in the system .

We achieved fairly good results using this non-tuneable $30 \mathrm{~kW}$ CW magnetron, supplied by CTL. Phase-locking technique is described in the previous publication [1]. However, the fact that the magnetron is non-tuneable and the complexity of the phase-locking set-up generated the idea of using a $30 \mathrm{~kW} \mathrm{CW}$ multiple beam klystron [8] with the characteristics very similar to the previously used $\mathrm{CW}$ magnetron. The new implemented technique permitted to substantially simplify the test set-up (Fig.8)

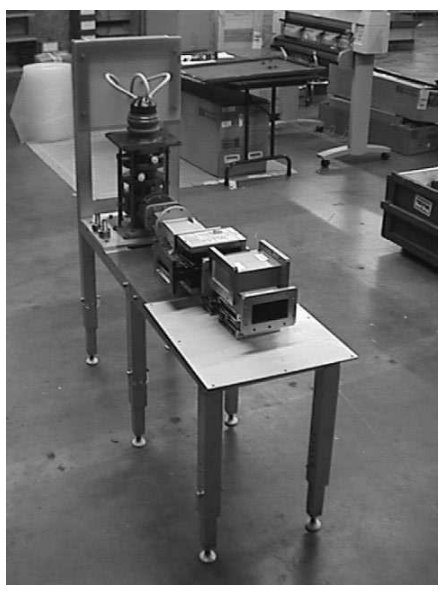

Figure 4: $30 \mathrm{~kW}$ multibeam CW klystron, circulator and cross-guide coupler assembled on a strongback.

The same Spellman MG48 power supply was used to drive the klystron, which has the similar loading characteristics and operates at anode voltage of $14 \mathrm{kV}$. The klystron is equipped with PPM focusing system, which eliminated the need for a solenoid. Two $12 \mathrm{~kW}$ inverter modules were added to the existing four to compensate for the lower efficiency factor. The automatic filament current runback for the klystron is not necessary, so it was disabled.

\section{HIGH POWER TESTING}

During the high power tests, we achieved maximum current of $4 \mathrm{~mA}$ at $1 \mathrm{MeV}$. Imaging tests have been successfully performed using the AS\&E detectors. We are continuing commissioning of the accelerator.

The first tour of experiments has been completed. The next phase of the development is to improve the design of the accelerator to create a deliverable product.

\section{REFERENCES}

1. Portable Linac using $\mathrm{CW}$ magnetron as Power source Proceedings of EPAC 98

2. A.S.Alimov et al Compact Two Section CW Electron Linac With High Beam Power, Preprint INP MSU 94 - 34/356, Moscow, 1994.

3. A.V.Mishin, R.G.Schonberg CW Particle Accelerator with Low Particle Injection Velocity, US Patent 5,744,919, 1998, priority 12/96.

4. American Science and Engineering Advertising Brochures.

5. ADMIT Corp. CW Klystron KIU-388DD, Advertising brochures. 